\title{
The First Wave: Chinese Film Music in the 1930s
}

\author{
Di Liu \\ Foreign Languages Studies \\ Anshan Normal University \\ Anshan, Liaoning Province, China \\ E-mail: lydia7384@hotmail.com
}

\begin{abstract}
Chinese cinema experienced a new epoch from 1932 to 1937: known as the left wing cinematic period. Almost a hundred films came into being during this period, which took on the instructive meaning of anti-imperialism and antifeudalism. This paper highlights the experience of Chinese film music in Shanghai left-wing cinema; Chinese film music as the national arts movement in the 1930s. This paper also takes Street Angel (1937) as a case to explore how Chinese film music technology and characteristics were developed in the 1930s.
\end{abstract}

Keywords-left-wing cinema; artistic movement; film music technology; characteristic

\section{INTRODUCTION}

In order to understand the first wave of Chinese film music (1930s), it is necessary to place these developments in the specific historical and cultural context of their production because understanding the history of 1930's China is the most important key to study Chinese film music in this contemporary period.

Generally speaking, Chinese cinema experienced a new epoch from 1932 to 1937: known as the left wing cinematic period. Almost a hundred films came into being during this period, which took on the instructive meaning of antiimperialism and anti-feudalism (Zhang, 1999). In comparison to 1920's production, these films are noted for their high quality visual effects. The 1930s were the high point for left wing cinema, especially for the film music (Zhong, 2002). Consequently, film/theme song creation became the most significant part of the viewing experience. However, this first climactic height definitely relied on the foundation of some film companies in Shanghai such as Mingxing and Tianyi (Zhang, 1998: 30-31).

\section{THE SituAtion IN SHANGHAI}

Shanghai in the 1930s was not atypical of cosmopolitan developments in China at large. It was, in many respects, one of the most westernized centers in China and it was renowned for its thriving a vanguard culture. According to Karen Lai and Sunny Ma, Shanghai was also noted for its thriving film industry and could be best described as China's only film producing metropolitan (Lai \& Ma, 1993: 15-16).

Since the 1911 Revolution, Shanghai had been one of the two political centers in China, the other one was Beijing. In the conflicts of interest and divergence of viewpoints among its population, Shanghai displayed a multi-faceted character in the life style of its citizens and this fact was reflected in the many movies made in Shanghai between 1930 and 1949 (Lai \& Ma, 1993: 16-17). This was an extremely important period in the history of Shanghai and China. Mingxing and Tianyi are the foundation of the first wave leftist cinema.

Strictly speaking, Zhang Shichuan, Zheng Zhenqiu are the early pioneers of Chinese films. They established Minxing Film Company (Star) in 1922 (Zhang, 1998: 31). Mingxing focused and specialized in family drama with the emphasis on traditional ideologies; thus situations which were close to "butterfly literature" (Zhang, 1998 and Zhong, 2002). The film company Tianyi developed its brand name by adapting folktales popular among audiences (Zhang, 1998). In addition, Tianyi's main target was the investment in Southeast Asia; it also focused on building its own theatre chain. However, since film productions were under foreign control and there was no relative integration of the industry, it seemed that the prospects for Chinese cinema were vague (Cheng-tsui.com, 2002). Some businessmen-producers were aware of the situation and attempted to build Chinese cinema networks but it required time and money, both in short supply when cinema approached the sound era during economic depression (Leung, 1993). What kind of phenomenon would appear in China given this historical background?

\section{Chinese NATIONAl Cinema AS THE ARTistiC MOVEMENT IN SHANGHAI 1930S}

The 1930s witnessed a new stress on trying to construct an idea of nationality in Chinese cinema (Zhang, 1999). This involved a reaction against old conventions and costumes, which came to be associated with elitist values. Notable for the production of this type of film was Luo Mingyou, a theatre-chain owner organized Lianhua (United Photoplay Service) in 1930. With its slogan to "revive national cinema", Lianhua produced films that attracted the attention of urban intellectuals (Zhang, 1999: 4). Prior to this, this group had been influenced by Kongfu films in the late 1920s (Sun, 1995: 35-36).

Before the Sino-Japanese war, many Chinese films were made and great works began to emerge. During this period,

\footnotetext{
${ }^{1}$ See Zhang Yingjin (1998) and Zhong Dafeng (2002). Both claim that this type of film had more in common with popular urban fiction, which was steeped in conservatism than with May Fourth literature.
} 
the main characters of films included refugees, farmers, fishermen, factory workers, child laborers, new-age women who worked outside instead of doing house work at home, city residents, and war heroes, and so on (Lai \& Ma, 1993: 17-18). With various different styles of creativity emerging, the stories behind the films become deeper and more artistic (Facets.com, 2000).

In 1935, Russia invited thirty-one countries to submit their best film in the first Moscow International Film Festival. The Chinese film Yuguang Qu (Song of the Fisherman, dir: Cai Chusheng, 1934) won the ninth place in the competition. The judges applauded the director Cai Chusheng who "bravely showed the life and great qualities of the Chinese people in a mainstream film." (Cheng-tsui.com, 2002: 6) This was the first time a Chinese film had accomplished a place in the international film festival.

Many great generational films were made in the 1930s. Films such as Wu Yong Gang's Shen Nü̈ ( The Goddess, 1934), Yuan Muzhi's Malu tianshi (Street Angel, 1937) Shen Xilin's Shizi Jietou (The Crossroad, 1936), Ying Yunwei's Taolijie (The Plunder of Plum and Peaches, 1934) and so forth. These strongly emotional films had a major impact on Chinese society and gave the viewers a sense of liveliness and vivacity (Hanhai.com, 2003). In addition to this, these films were of high artistic quality. When in 1984, these 1930s Chinese films were showcased in Italy, Europeans were amazed at their high quality and artfulness (Chengtsui.com, 2002). Another key element to this artistic quality was film music. I will address the issue of why and how the film music group worked in the next section.

\section{Theme Song/Pop Song AS A New ART Style OCCURRING IN 1930S CHINESE CINEMA}

In the spring of 1932, the Chinese Communist Party film production group was founded formally (Lai \& Ma, 1993: 15). Under the leading and guidance of the Chinese Communist Party, some progressive film producers, and film makers became the cadres. After the long time hardship, Chinese film makers had obtained some power to control some film companies (Zhu, 2003: 89). This gave rise to the majestic left wing film arts movement and within this, Chinese national film music came into its first wave.

\section{A. The Debates on Chinese Film Music in Shanghai in the 1930s}

The importance of music in the making of the metropolitan, modern culture of China in the 1920s and the 1930s has been noted by Sue Tuohy (Tuohy, 1999: 200-207). As Tuohy pointed out:

- Music plays a pivotal position in experiments conducted by Chinese intellectuals with techniques and modes of filmic representation. Indeed, music occupies a crucial position in Chinese film historiography. In particular, the cross-media linkage of music with moving images signifies the ambivalence Chinese intellectuals felt toward Western culture (Tuohy, 1999: 220).
Another leading left-wing film critic Wang Chengwu noted how this ambivalence is expressed in his paper 'The Chinese Cinema Orientation' (1935):

- The great film must go deep into the mass, it must bring the effectiveness after being understood by everyone ... as for the film content, it should reflect the real life of the masses, and the main characters should come from the masses; while for the film format, it should outspread in a very lively way, more action, less dialogue (Wang, 1935:2).

As a result of this argument, Chinese film music creativity during this period grasped the representative significance of the theme song in film. This proved to be an advance on the use of theme song as solely instrumental music.

However, the type of film song produced also depended on people's music appreciation level at that time. There is no question that the Chinese people's music appreciation ability was very low during the period (from 1920 to 1930); they could not understand the meaning which was transformed by the instrumental music completely (Wang, 1995:67-68). Because of the non-objectivity of the instrumental music, generally speaking, it could however be understood by people whose musical literacy was at a higher level. The creation of theme/film songs was based on a combination of lyrics and melody; this transferred the feeling which was aroused by the music to the experience mediated by the music image. In addition, film songs combined both visual image and sound effect (music) in one movie (Zhang, 2004: 76-78).

While some instrumental music has this kind of combination, the film song was able to be more direct, more popular, and more understandable. Lü Ji, a famous Chinese composer notes:

- If we talk about the music itself, instrumental music is more powerful than film/theme song, however, in the 1920s, Chinese music instruments had not achieved the perfect level, the cooperation between different instruments had not based on the scientific method. Moreover, many Chinese people had not been well educated in music literacy, it was impossible for them to understand the pure instrumental music, and thus film/theme song showed its power more than instrumental music. It is indeed because that film/theme song creation is based on the literature and language. It can easily transfer the instructive meaning to every singer or even every audience. Therefore, in my view our national music should focus on theme songs creation nowadays (Lü, 1936: 11).

While Lü Ji comments on Chinese national music in general here, the situation of left wing film music was similar, it focused on film/theme song creation at the beginning of the 1930s.

Despite sound movie production being started in China as early as 1930, the production of silent movies was not 
over until 1936. From the discussion about the future of sound movies which was published in March, 1930, Tim Brace affirms that sound movies were "the new born infant who will welcome the great future" (Brace, 1991: 55). Up until the Chinese Communist Party founded formally in March, 1933, there had been heated debates about the respective merits of silent and sound movie. This was fuelled by the fact that, in some instances, sound movie production was not of a very high quality (in some films it merely involved the addition of arbitrary music and dialogue to the original silent version) (Bohlman, 1988: 34). One of the results of the Chinese Communist Party film production group coming into existence was the establishment of the left wing music score group. Tian Han, An E, composer Ren Guang, Nie Er, Lü Ji, who were the most important members and others participated in film making quickly; the outcome being that Chinese film music took on a new dimension, so much so that it spread and influenced Chinese music styles for a whole generation in the 1930s.

\section{B. Li Jinhui and Shi Dai Qu (Popular songs)}

In 'Ten Days' Talk on Popular Songs' (1991), songwriter Situ Ming notes:

- Shi Dai Qu was first written by Li Jinhui. His style of New Songs was dismissed by academic musicians of Shanghai as Li style songs. Shi Dai Qu (popular songs) is the term used in Shanghai, and were called New Songs when they first appeared ... To win a wider audience, clever songwriters began to combine western music with regional Chinese tunes (Situ, 1991: 22, cited in Ho, 1993: 59).

Musically speaking, most of Li Jinhui's works are concentrated on compositions "essentially a kind of signified jazz which fused Western instrumentation and harmony with largely pentatonic Chinese folk melodies" (Wong, 1996: 98). Also, as in Li Jinhui's songs, lyrics are generally romantic in content, and performed with a gentle, mellow vocal style quite unlike that of traditional Chinese folk song or opera (Ho, 1993).

Shi Dai $Q u$ became very popular in Shanghai in the late 1930s, and entered its period of gigantic popularity during a time of national crisis. Shi Dai Qu's first generation of singers was recommended by Li Jinhui, and one of them was called Lan Ping who later made a career in movies. After marrying Mao Zedong, Lan Ping changed her name to Jiang Qing and later became a member of the Gang of Four (Wong, 1993: 56-58).

\section{Nie Er, He Luting and Chen Gexin}

Nie Er was born on 15th February, 1912 and began his career as a songwriter working under Li Jinhui. With the attack by Japan on the Zhabei district in Shanghai in 1932, and in the debates of heightened Chinese nationalism that followed Japanese aggression during the 1930s, Nie Er turned away from popular music (mainly signified by Jazz) and began writing revolutionary music for left wing films (Sun, 1979: 40-41). He created a sense of heroic Chinese nationalism in his music through the tone of March and patriotic lyrics, and thus he earned a high reputation among leftists and communists (Brace, 1991: 43-47). After the liberation war of 1945, the film song March of the Volunteers which was written by Nie Er eventually became the People's Republic of China's national anthem, and hence it makes an important turning point in the history of modern China (Wang, 1995: 65). Since then, Nie Er has been regarded as a revolutionary hero in the People's Republic of China.

The war against Japan from 1937 to 1945 influenced the people of Shanghai (like the rest of China) and turned them into the most passionate community supporting China to fight for the survival of the Chinese people (Sun, 1995: 2-4). Musicians in Shanghai were noted for their many and varied skills and abilities, with the Shanghai Music Conservatory being the cradle of music education of art music, the compilation and study of folk music, as well as the writing of popular songs (Leung, 1993: 47). As a consequence, Shanghai film and music production influenced the development of Chinese cinema before 1949. For example, He Luting, who was well known for his short piano piece Buffalo Boy's Flute (Mutong duandi), also wrote popular songs for several movies, and the most successful one being Autumn River and Dream Lover in the movie The Ancient Pagoda Murder Case (1939). According to Shi Zhongxing, He Luting "emphasized the beauty of traditional music and particularly the need to take advantage of that tradition." (Shi, 1990:73) He believed that only by adopting a mixed approach would new Chinese music establish a solid structure and arouse nationalist feelings. His convictions soon brought him together with leftist artists (Yeh, 2002: 84$85)$.

The best-known and the most talented composer of theme songs was Chen Gexin, who is rightfully named by Paul Leung as the "Father of Chinese Popular Songs" (Leung, 1993: 48). According to Karen Lai and Sunny Ma (1993), one happy coincidence was the fact that the recording company in Shanghai (Pathè) in the 1930s engaged in making records for Chinese pop music and this company had the fortune to sign an exclusive contract with Chen Gexin. The happy partnership between Chen and the Pathè Record Company ensured that Chen Gexin's songs could reach a popular audience while the record company could rely on Chen Gexin for a steady supply of movie songs (Lai \& Ma, 1993: 79).

During the 1930s, when Shi Dai $Q u$ began to emerge as a distinct art form, quite a few composers were active in Shanghai. Drawing on Paul Leung's four basic classifications ("talent, training, personality, and style"), I will now evaluate the achievement of pop songwriters (Leung, 1993: 50). The first type I would classify as being talented but under-trained, Nie Er is a good example of this grouping. Nie Er wrote many outstanding pop songs utilizing the traditional Chinese pentatonic scale. All of these songs demonstrated an innocent and simple natural flavour like a genuine folk song and even professional composers could not easily achieve such a level. Another member of this group Xian Xinhai was trained but still under talented. Chen Gexin is both talented and well trained. He was perhaps the 
only one among the first generation of composers in China who read books on Western classical music.

\section{The "Golden Voice" Zhou Xuan (1920-1957)}

Born in Changzhou (quite close to Shanghai), Jiangsu Province, she was as a child sold from age four on as a stepdaughter to a succession of opium addicts, thus Zhou Xuan experienced her unfortunate childhood (Chinabroadcast.net, 2005). Since 1936, Zhou Xuan began her actress career in a series of films including Street Angel, Dark Night, Night Inn, Menglijun, Recall to the Jiangnan and so on. Music was very much part of these films: for example, in Street Angel, Zhou Xuan played a female singer who was suffering great insult, but who still held positive optimism towards the future. The film enjoyed great success on its release. Moreover, its two theme songs Si Ji Ge (Song of Four Seasons) and Tian Ya Ge Nü (Songstress of the World), both sung by Zhou Xuan, were also popular with Chinese audiences (Stock, 1993: 13-14). From then on, Zhou Xuan became one of the top female singer-actresses in China. In short, through Street Angel, the popular movie in the late 1930s in China, people got to know "golden voice" Zhou Xuan, one of the few highly successful singer-actresses during the period of the 1930s, 1940s, and even in the 1950s in China (Yi, 1992: 277).

\section{The OUtSTANDING LEFTIST COOPERATION: StREeT ANGEL (1937)}

As noted earlier, Chinese cinema in the 1930s is characterised by a synthesis of native art and foreign modes of production. During this period, on the one hand, Chinese filmmakers considered cinema as a specifically Western invention; on the other hand, they also felt compelled to incorporate native forms suitable for Chinese audiences (Yeh, 2002). Concerning the film music, it appears both irregular and contradictory in perspective. This is evidenced by the use of a substantial amount of Western classical music, and by an emphasis on the ingenuity of Chinese local music. In the early years of sound movies, it was convenient for Chinese filmmakers to use Western music to fill up with soundtrack, but it was hard for Chinese audiences to understand the filmic meaning and also problematic for Chinese artists who were intent on emphasising China's national characteristics.

Hence, leftist filmmakers and musicians made an extra effort to feature Chinese-style music in addition to Western melodies. They incorporated Chinese music in the story by making the character either sing or play an instrument. For example, in his book Looking for the Trace of Chinese Film Music, Wang Wenhe lists The Plunder of Plum and Peach (1934, Diantong), Street Angel (1937, Mingxing) as landmarks in the history of Chinese film music (Wang, 1995: 12-14). Wang Wenhe's selection shows the common musical practice used in these four films: almost all the songs were written by Chinese composers. As for the theme songs written by Chinese musicians during the 1930s and the 1940s, historians often identify them as the key to the popularity of the leftist classics. One prominent example is Street Angel.
In this film, the two Chinese folk songs Song of Four Seasons and Songstress of the World are considered essential to the film's success in the 1930s and the 1940s. This accomplishment belongs to the lyricist Tian Han and the young composer He Luting. According to Shi Zhongxing, when Tian Han wrote scripts for films, he also produced lyrics for composers to use later on. When Yuan Muzhi was making Street Angel, he asked He Luting to rearrange two Suzhou folk songs for the film (based on the traditional music of a southern canal city near Shanghai). Through his rewriting, the provincial melodies turned into national hits with features of "Chineseness" (Shi, 1990: 73).

In Song of Four Seasons, for example, we hear a pentatonic melody, rhythm, instrumentation, and singing combined into one song that evokes wartime Chinese patriotism. He Luting chose to use traditional instruments and "golden voice" Zhou Xuan to sing the song. With the Chinese instruments erhu (a vertical two stringed fiddle), pipa (plucked lute), sanxuan (a vertical three stringed fiddle), and ban (wooded clapper) playing the overtone, followed by Zhou Xuan's unique narrow voice style (Chinese folk vocal style) interpretation, audiences could easily recognize its association with a traditional musical style. Film director Yuan Muzhi and music composer He Luting experimented with the use of music for film at the same time. For example, when this theme song was played as diegetic music and the image was synchronised, the synchronised relationship between music and image helped audiences understand the film story synopsis easily. Since then, synchronism between music and image was adopted in Chinese cinema widely.

Furthermore, the song's lyrics describe a woman's lovesickness for her husband, who is away fighting invaders. At the same time, the scene describes the sufferings of ordinary people by playing pseudo documentary war footage on the image. This is significant because in the late 1930's Shanghai, the KLM exercised tight control over cultural production. Any reference to Japan's invasion was banned in order to prevent people from expressing anger towards Japan for its military aggression. However, by using a love song to define and complement the images of the old northeast damaged China, the film Street Angel could strongly deliver its message of condemnation of the Japanese invasion without arousing the censors (Shi, 1990). At this moment, the image describing the plot paralleled with the Song of Four Seasons appears as nondiegetic theme; this is considered to be the first use of parallel relationship between music and image in Chinese cinema.

In a word, Song of Four Seasons played an important role in the narratives of left-wing artists. He Luting and Yuan Muzhi's cooperation in music and image relationship demonstrated how Chinese artists were experimenting with sound and image (Wang, 1995: 56). The synchronised relationship between music and image became a useful film technique and also one that is still popular in Chinese cinema. The parallel relationship was experimented with, firstly, by contemporary Chinese filmmakers and musicians. 


\section{CONCLUSION}

This paper highlights the experience of Chinese film music in Shanghai left-wing cinema in the 1930s, it also takes Street Angel (1937) as a case to explore how Chinese film music technology and characteristics are demonstrated in the 1930s.

The splendid film song creation of the 1930s represents both of the two perspectives on the creative transition from simple to mature perspective. Firstly, the relationship between music and image was upgraded to a blend of sound and image, rather than merely music synchronizing extremely with pictures on screen. Secondly, as the relationship between music and other sound elements, although the oneness of pure music has not been substituted by the all-round film music, it had been realized and balanced in association with sound. Moreover, the achievement of outstanding film songs in the 1930s provides a good example of blending nationality with modernity. It draws on the mainstream Western music, incorporating Chinese native music, especially when used for the representation of Chinese nationality. This made it easily understood by a mass cultural audience, particularly relevant to China at this time

\section{REFERENCES}

[1] Brace, Tim, 'Popular Music in Contemporary Beijing: Modernism and Cultural Identity', Asian Music, 22 (2), 1991, pp.43-66.

[2] Ho, Sam, 'The Songstress, the Farmer's Daughter, the Mambo Girl, and the Songstress Again', in Law Kar (ed.) Mandarin Film and Popular Songs: 1940-1990, Hong Kong: Urban Council, 1993, pp. 59-68

[3] Lai, Karen and Sunny Ma, 'Two or Three Things about Mandarin Pop: An Interview with Wong kee-chee', in Mandarin Films And Popular Songs 40's-60's: The 1 $7^{\text {th }}$ Hong Kong International Film Festival, Hong Kong: Automatic Printing Company, 1993, pp. 1518,79 .

[4] Leung, Paul, 'Mandarin Movies and Mandarin Pop Songs', in Mandarin Films And Popular Songs 40's-60's: The 17 th Hong Kong International Film Festival, Hong Kong: Automatic Printing Company, 1993, pp.47-50.

[5] Lŭ, Ji, Talking about the Chinese National Music, Shanghai: Shanghai Movie Press, 1936, pp.11.

[6] Shi, Zhongxing, Biography of He Luting (He Luting Zhuan), (2nd ed.), Shanghai: Shanghai Wenyi Press, 1990, pp.73.

[7] Stock, Jonathan, 'Reconsidering the Past: Zhou Xuan and the Rehabilitation of Early Twentieth-Century Popular Music', Asian Music, 1993, No. 4: 11-14

[8] Sun, Shao-yi, 'Urban Space and Chinese Nationalism: Re-reading Chinese Leftist Films of the 1930s', Paper presented at The 1995 Annual Meeting of the Western Conference of the Association for Asian Studies, Honolulu: Hawaii, 1995, pp. 2-4, 35-36

[9] Sun, Yu, Recall My Early Film Creation, Shanghai: Shanghai Movie Press, 1979, pp.35-43.

[10] Tuohy, Sue, 'Metropolitan Sounds: Music in Chinese Films of the 1930s', in Yingjin Zhang (ed.) Cinema and Urban Culture in Shanghai, 1922-1943 Stanford, Calif.: Stanford University Press, 1999, pp.200-221.

[11] Wang, Chenwu, The Chinese Cinema Orientation, Beijing: Beijing People Press, 1935 pp.2.

[12] Wang, Wenhe, Looking for the Trace of Chinese Film Music (Zhongguo Dianying Yinyue Xunzong), Beijing: Zhongguo guangbo dianshi chubanshe, 1995, pp. 11-68.
[13] Wong, Kee-chee, 'Pathè: Evolution of a Record Company', in Mandarin Films and Popular Songs 40's-60's: The 17th Hong Kong International Film Festival, Hong Kong: Automatic Printing Company, 1993, pp. 56-61.

[14] Yeh, Yueh-yu, 'Historiography and Signification: Music in Chinese Cinema of the 1930s', Cinema Journal, 41, (Spring), 2002, No.3: 8389

[15] Yi, Ren, A Biographical Sketch of Zhou Xuan, Shanghai: Shanghai Music Press, 1992, pp. 277-280.

[16] Zhang, Wei, A Special Scanning for the China Early Cinema, Shanghai: Cishu Publishing House, 2004, pp. 34-78.

[17] Zhang, Yingin (ed.), China in a Polycentric World: Essays in Chinese Comparative Literature, Stanford, CA: Stanford University Press, 1998, pp.23-33.

[18] Zhang, Yingin (ed.), Cinema and Urban Culture in Shanghai, 19221943, Stanford: Stanford University Press, 1999, pp.4.

[19] Zhong, Dafeng, 'Chinese Cinema as the Reformation of Arts in 1930s', in Lu Hongshi (ed.) Chinese Cinema: Representation and Examination, Beijing: China Movie Press, 2002, pp.65-67.

[20] Zhu, Ying, Chinese Cinema during the Era of Reform: The Ingenuity of the System Westport, Connecticut and London: Praeger Publishers, 2003 pp. 89.

[21] Cheng \& Tsui homepage, http://www.cheng-tsui.com, 2000.

[22] China Broadcast site, http://en1.chinabroadcast.net, 2005.

[23] Facets Video, http://www.facets.org, 2000.

[24] Han Hai Video, http://www.hanhai.com, 2003.

[25] Malu tianshi (Street Angel, dir: Cai Chusheng, Yuan Muzhi, 1937), Filmography

[26] Shennŭ (The Goddess, dir: Wu Yonggang, 1934), Filmography

[27] Shizijietou (Crossroad, dir: Shen Xiling, 1937), Filmography

[28] Taolijie (The Plundered of Peach and Plum, dir: Ying Yunwei, Yuan Muzhi, 1934), Filmography

[29] Yuguang qu (Song of the Fisherman, dir: Cai Chusheng, 1934), Filmography

[30] Yuguotianqing (The Bright Sky, dir: Cai Chusheng, 1931), Filmography 